\title{
SOLAR POWER MICROINVERTER
}

\author{
NAGY Zoltan Tamas \\ University of Oradea \\ Oradea, Romania \\ znagy@uoradea.ro
}

\author{
GERGELY Eugen Ioan \\ University of Oradea \\ Oradea, Romania \\ egergely@uoradea.ro
}

\author{
COROIU Laura \\ University of Oradea \\ Oradea, Romania \\ coroiu@uoradea.ro
}

\begin{abstract}
In our days people put accent on using green energy. One such possibility is the use of solar power systems. The problem that occurs is to deliver the obtained power into the grid. In this paper we describe a microcontroller based inverter to obtain the synchronous power which was delivered in the grid.
\end{abstract}

Keywords - Solar power cell, microinverter, microcontroller, green energy

\section{INTRODUCTION}

Renewable resources, such as wind generation systems and Photovoltaic (PV) systems, have gained great visibility during the past few years as convenient and promising, renewable energy sources. There are several benefits for solar power systems, such as:

- Clean and renewable energy that replaces power produced by coal, oil and nuclear power

- Reduction/elimination of electric bills

- Silicon for manufacturing PV panels is the second most abundant element on Earth

- The ability to provide power to remote locations.

The recent increase in demand for solar power systems is due to enhancements in manufacturing crystalline panels, which reduces overall costs in manufacturing and increases the efficiency of the PV panels [1]. Additional reasons for the demand in solar power are: PV technology is proven and reliable, PV modules have warranties exceeding 30 years and government incentives.

\section{OVERVIEW}

There are two main requirements for solar inverter systems: harvest available energy from the PV panel and inject a sinusoidal current into the grid in phase with the grid voltage. In order to harvest the energy out of the PV panel, a Maximum Power Point Tracking (MPPT) algorithm is required. This algorithm determines the maximum amount of power available from the PV module at any given time. Interfacing to the grid requires solar inverter systems to abide by certain standards given by utility companies [2].

To begin development of a solar microinverter system, it is important to understand the different characteristics of a solar cell. PV cells are semiconductor devices with electrical characteristics similar to that of a diode. However, a PV cell is a source of electricity and operates as a current source when light energy, such as sunlight, makes contact with it. The most common technologies today are the monocrystalline and multi-crystalline silicon modules [3]. A PV cell can be modeled as shown in Fig. 1. Rp and Rs are parasitic resistances that, in an ideal world, would be infinite and zero, respectively.

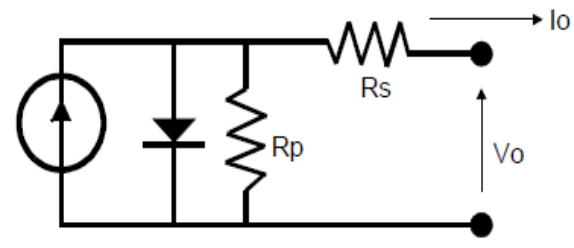

Fig. 1: Simplified model of a PV cell.

Light intensity and temperature largely impact the operating characteristics of a PV cell. Current is directly proportional to light intensity, but the change in illumination has little impact on the operating voltage. The operating voltage is, however, impacted by temperature. An increase in cell temperature will decrease the operating voltage, but will have little effect on the generated current. The influence of temperature and illumination on a PV module is illustrated in Fig. 2.

\subsection{Maximum Power Point (MPP)}

A solar cell may operate over a wide range of voltages and currents. By continuously increasing the resistive load on an irradiated cell from zero (short-circuit event) to a very high value (open circuit event), the MPP can be determined. MPP is the operating point that maximizes, $\mathrm{V} \mathrm{x} \mathrm{I}$, and delivers the maximum power at that irradiation. The output power in a short-circuit (PV voltage equals zero) or open circuit (PV current equals zero) event is zero.

A high quality, monocrystalline silicon solar cell, at $25^{\circ} \mathrm{C}$ cell temperature, may produce 0.60 volts open circuit. The temperature on a given cell in full sunlight, with an air temperature of $25^{\circ} \mathrm{C}$, may be closer to $45^{\circ} \mathrm{C}$ which will reduce the open circuit voltage to $\sim 0.55 \mathrm{~V}$. As temperature rises, the open circuit voltage continues to drop until there is a short circuit on the PV module. The maximum power at a cell temperature of $45^{\circ} \mathrm{C}$ is typically produced with $80 \%$ of the open circuit voltage and $90 \%$ of the short-circuit current. The short-circuit current from a cell is nearly proportional to the 
illumination, while the open circuit voltage may drop $10 \%$ with an $80 \%$ drop in illumination. Lower quality cells have a more rapid drop in voltage with increasing current, which would reduce the usable power output from $70 \%$ to $50 \%$ or even as little as $25 \%$.
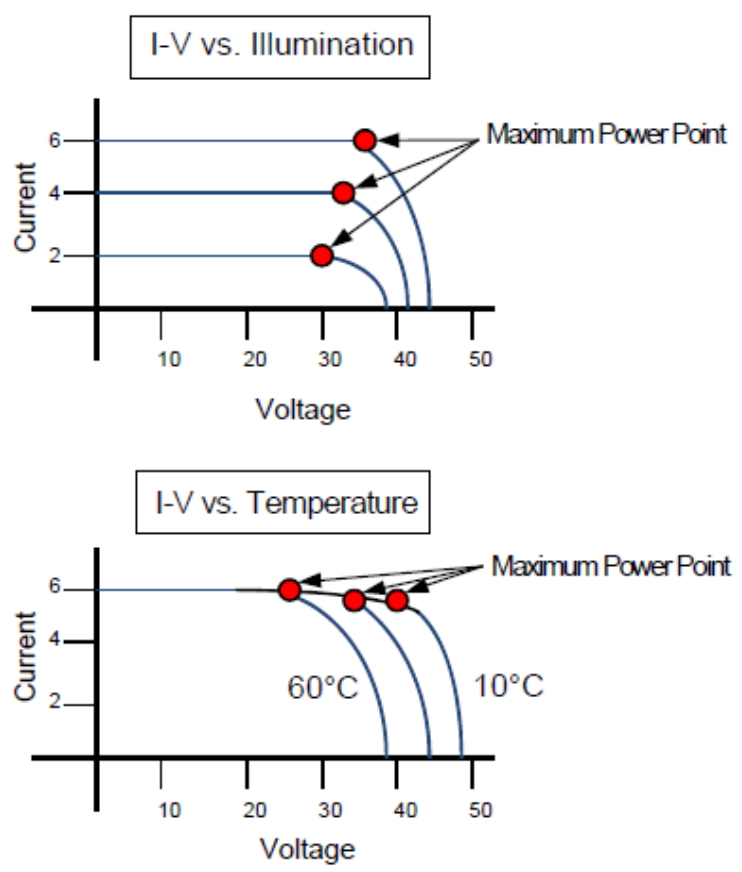

Fig. 2: PV module electrical characteristics.

\subsection{Grid-connected microinverter system}

A high-level block diagram of a grid-connected solar microinverter system is shown in Fig. 3.

The term, "microinverter", refers to a solar PV system comprised of a single low-power inverter module for each PV panel [4]. The advantages of a solar microinverter system include:

- Improvement of system reliability by reducing inverter temperatures and removing fans;

- Replacement of traditional hard switching techniques with soft switching techniques to improve efficiency and reduce heat dissipation;

- System designs can be standardized (hardware and software) to improve reliability and reduce costs.

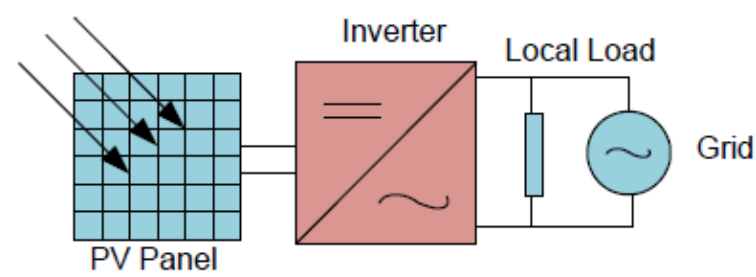

Fig. 3: Grid-connected solar microinverter system.

\section{HARDWARE DESIGN}

The Solar Microinverter Reference Design is a single stage, grid-connected, solar PV microinverter. This means that the DC power from the solar panel is converted directly to a rectified AC signal. This conversion is done by an interleaved flyback converter. A Full-Bridge (unfolding) converter, switched at $2 x$ line frequency, controls the direction of power flow to the grid. This microinverter has been designed to connect to any PV module having a power rating of approximately 250 watts, with an input voltage range of 25 VDC to $45 \mathrm{VDC}$, and a maximum open circuit voltage of $\sim 55 \mathrm{~V}$. The schematic diagram of the microinverter is shown in Fig. 4.

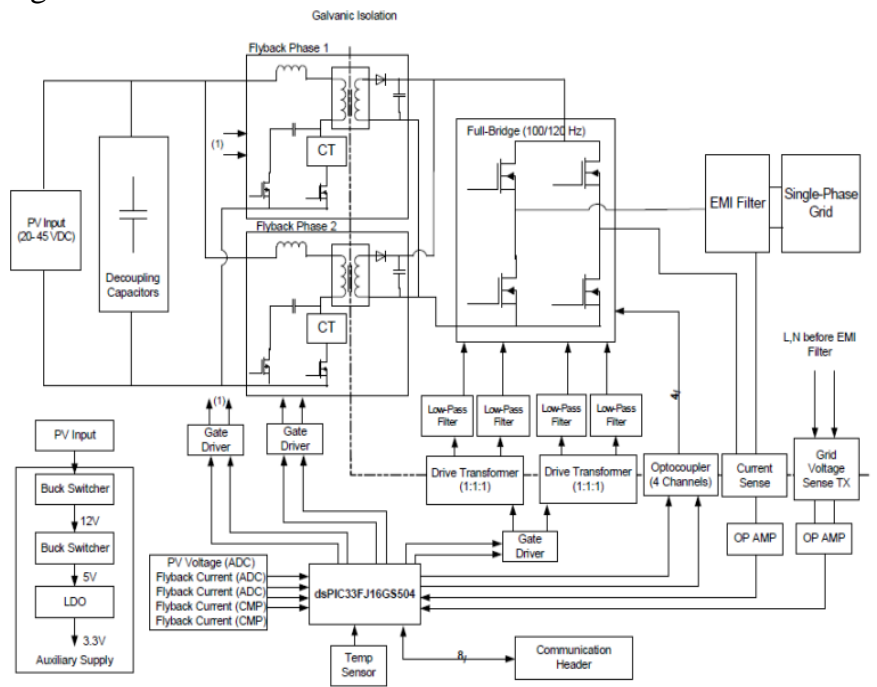

Fig. 4: Schematic diagram of the micro inverter system.

The operating waveforms of the unfolding bridge circuit are shown in Fig. 5. During one AC half cycle, PWM3H switches and drives one leg of the unfolding circuit (Q2, Q5). When the $\mathrm{AC}$ voltage approaches the zero cross, PWM $3 \mathrm{H}$ is disabled and the optocoupler is enabled (OPTO_DRV1). During the other half cycle, PWM3L drives MOSFET Q3 and MOSFET Q4. 


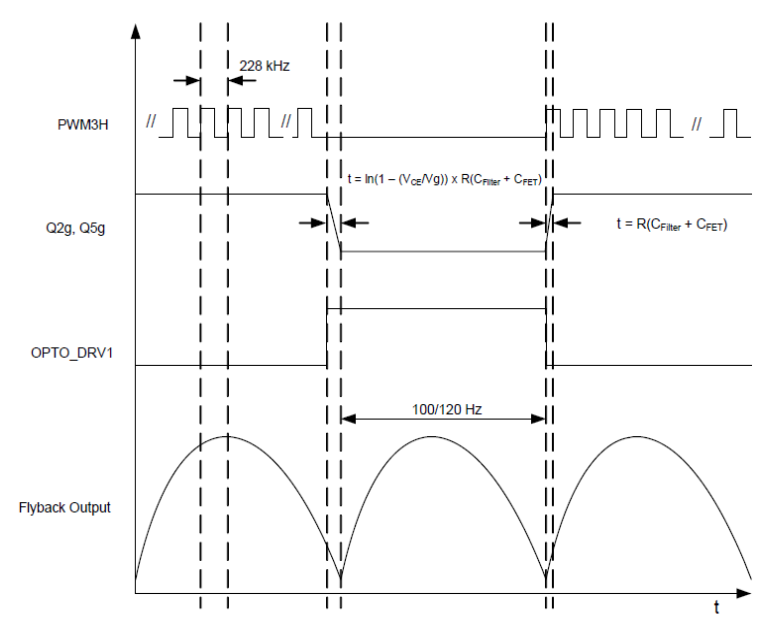

Fig. 5: Full-bridge operational waveforms.

\section{SOFTWARE DESIGN}

The Solar Microinverter Reference Design is controlled by a single dsPIC DSC device, as shown in the system block diagram in Fig. 6. The dsPIC DSC device is the heart of the Solar Microinverter Reference Design and controls all critical operations of the system as well as the housekeeping operations [5].

The functions of the dsPIC DSC can be broadly classified into the following categories:

- Digital Power Conversion Algorithms;

- State Machine for Different Modes of Operation;

- Maximum Power Point Tracking (MPPT);

- Digital Phase Lock Loop (PLL);

- System Islanding and Fault Handling.

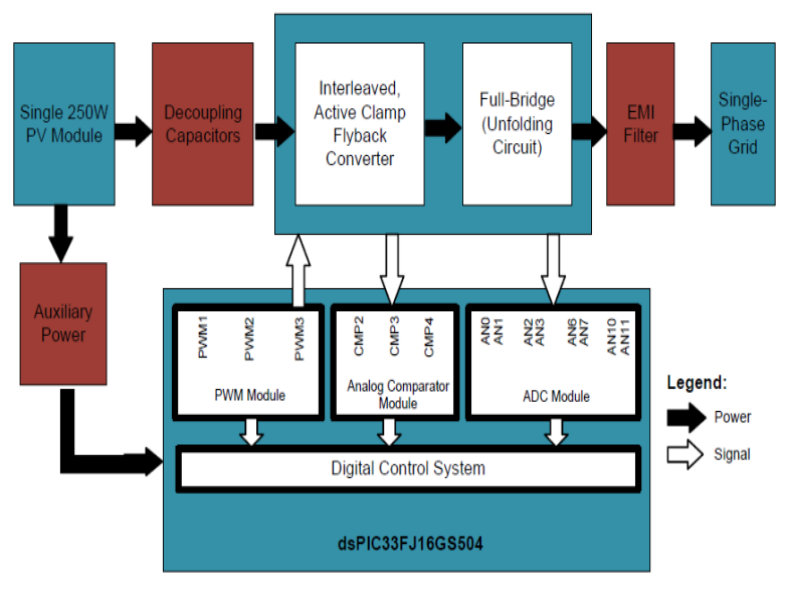

Fig. 6: System block diagram.

A high-level block diagram of the solar microinverter software structure is shown in Fig. 7. As shown in this figure, the software is partitioned into five parts:

- A User Interface;

- B; Timer2 Interrupt Service Routine (10 kHz):

○ MPP Tracking (AC Frequency/3)

○ Load Sharing $(5 \mathrm{kHz})$

- B; Timer1 Interrupt Service Routine $(3.3 \mathrm{~Hz})$

- A; ADC Interrupt Service Routine $(56 \mathrm{kHz})$

- B; Analog Comparator Interrupts

\subsection{State Machine}

The solar microinverter software implements a state machine to determine the mode of operation for the system. The state machine is executed, once every $100 \mu \mathrm{s}$, inside a timer Interrupt Service Routine (ISR).

As shown in Fig. 8, there are three system states: System Error, System Start-up and Day mode.

\subsection{Start-Up Routine}

The following section describes the start-up procedure for the solar microinverter. The system powers up in system error, but with no Faults detected. Once the on/ off switch is switched to the ON position, and no Faults are present, a restart counter of $500 \mathrm{~ms}$ starts. If no Faults have been detected for $500 \mathrm{~ms}$, the system will switch to Start-up mode. If, at any time a Fault occurs during the restart event, the restart counter is reset to zero and the system waits for the Fault to be removed before entering the restart counter routine. 
When the system enters Start-up mode, approximately 30 zero cross events are counted before enabling the full-bridge unfolding circuit. The unfolding circuit is enabled at the peak of the AC voltage to eliminate a large inrush current if enabled at the zero crossing. Approximately 30 zero crossings are counted after enabling the full-bridge, unfolding circuit before enabling the flyback converter. If, at any time, a Fault is detected, the system will switch back to system error. To enable the flyback converter, the system state machine switches to Day mode.

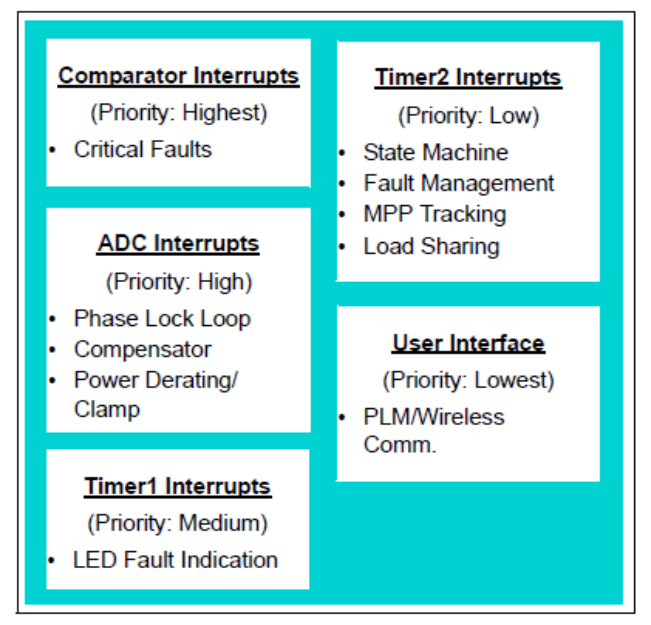

Fig. 7: High-level software block diagram.

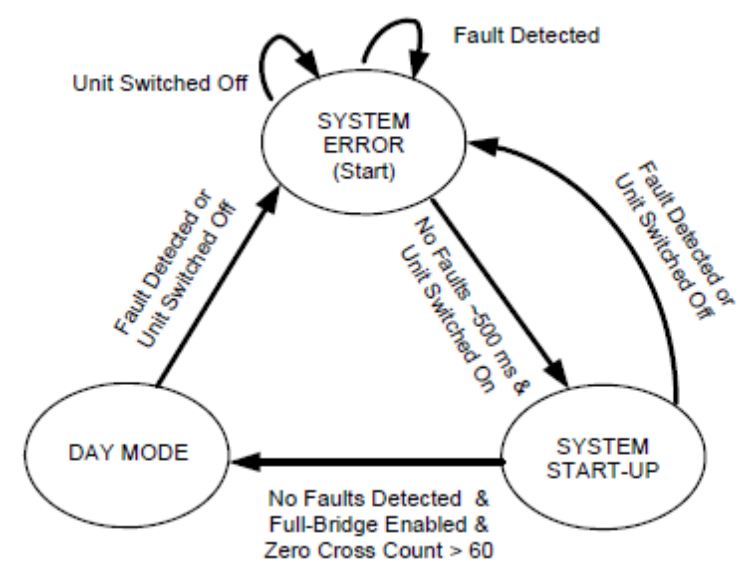

Fig. 8: State tranzition diagram.

\subsection{Day Mode}

Normal operation of the solar microinverter occurs during Day mode. In this mode, the solar microinverter is fully operational and is delivering the maximum available energy from the PV panel to the single-phase grid. The Maximum Power Point and load sharing functions are called in Day mode.
During this time, if a Fault occurs or if the on/off switch is switched to the OFF position, the system state will switch to a system error.

\subsection{Full-bridge (unfolding circuit)}

Figure 9 shows the flowchart for the state machine that has been implemented to control/determine the proper state for driving the full-bridge unfolding circuit.

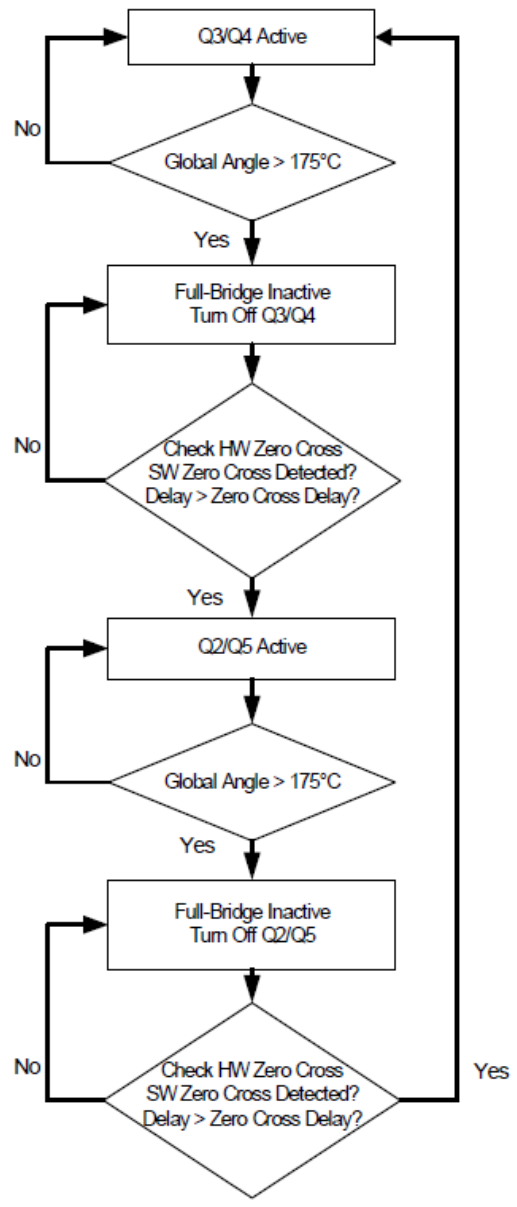

Fig. 9: Full-bridge flowchart.

There are four different states for the full-bridge state machine. Two of the states define an inactive region, and The other two states drive the full-bridge unfolding circuit. All PWM drive signals are in an override state when the state machine is operating in the inactive states. At each zero cross, the last known hardware zero cross state is compared against the new state to ensure that the hardware zero cross is functional. Before the state machine can switch to an active state, both the hardware zero cross and software zero cross events need to occur. The flyback output voltage never 
reaches zero volts. When the full-bridge MOSFETs are disabled near the zero cross, there will be some small voltage that remains $(\sim 15 \mathrm{~V})$ on the flyback output. Because of this, a small delay has been added to give time for the AC voltage to reach the approximated flyback output voltage. This will reduce/eliminate small glitches caused by the difference in voltages. The delay is different for $50 \mathrm{~Hz} / 60 \mathrm{~Hz}$ operation. When in an active state, the PWM drive signal remains active until the system global angle is greater than 175 degrees. This event occurs very close to the zero cross event. If, for some reason, the software zero cross is detected before the global angle is greater than 175 degrees, the state of the full-bridge drive is automatically changed to the proper inactive state (depending on the direction of the zero cross event).

\section{CONCLUSIONS}

In this paper we present a method to obtain the maximum power gived by our sun. It's necesary to develop new control systems and technologies to increase the conversion percentage of the solar power. This means two problems: develop new technologies to create greater eficiency PV solar power cells and to develop more efficient conversion control systems.

\section{REFERENCES}

[1] D. Briggs, D. Williams, P. Steele and T. Reed, "Bigger is Better: Sizing Solar Modules for Microinverters," Enphase Energy, Inc., October 25, 2012.

[2] E. J. Yoon and C. G. Yu, "A Micro-Scale Solar Energy Harvesting Circuit with MPPT Control for Self-Powered Systems," Future Information Communication Technology and Applications, Lecture Notes in Electrical Engineering, H. K. Jung, J. T. Kim, T. Sahama, C. H. Yang, Eds, Springer, Vol. 235, pp. 499-508, 2013.

[3] M. Kaltschmitt, W. Streicher and A. Wiese, Eds., "Renewable Energy," Technology, Economics and Environment, Springer, 2007.

[4] L. Jianxiang, Z. Qiangsheng and C. Huimin, "A Portable Solar Power Supply Device with High-Efficiency Inverter," Proceedings of ISES World Congress 2007, in "Solar Energy and Human Settlement," Goswami, D. Yogi; Zhao, Yuwen, Eds. Springer, pp. 1473-1477, 2009.

[5] Z. T. Nagy, E. I. Gergely, "Microstepping Driver for Step Motors, "Journal of Computer Science and Control Systems, Vol. 4, Nr. 1, pp. 107-110, 2011.

[6] G Husi;I Bartha; A Vitéz: Study of solar cell energy production mounted on a four way rotating device in: Study of solar cell energy production mounted on a four way rotating device, designed for electrical car recharging.Budapest, Magyarország, 2013.03.16-2013.03.21.

[7] Bartha István; Tóth János;Husi Géza: Effect of a Four-Way Rotating Device To The Electric Energy Production With Solar Cell, Analele Universitatii Din Oradea Fasciola Management Si Inginerie Tehnologica (ISSN: 1583-0691) X (XX): (3) pp. 2.92.16. (2011) 